\title{
Context-specific complementary feeding recommendations developed using Optifood could improve the diets of breast-fed infants and young children from diverse livelihood groups in northern Kenya
}

\author{
Marieke Vossenaar ${ }^{1}{ }^{*}$, Frances A Knight ${ }^{1}$, Alison Tumilowicz ${ }^{1}$, Christine Hotz ${ }^{1}$, Peter Chege $^{2}$ \\ and Elaine L Ferguson ${ }^{3}$ \\ ${ }^{1}$ Global Alliance for Improved Nutrition (GAIN), Rue de Vermont 37-39, CH-1202 Geneva, Switzerland: ${ }^{2}$ Kenyatta \\ University, Nairobi, Kenya: ${ }^{3}$ Faculty of Epidemiology and Population Health, London School of Hygiene \& Tropical \\ Medicine, London, UK
}

Submitted 21 June 2106: Final revision received 22 September 2016: Accepted 3 October 2016: First published online 5 December 2016

\begin{abstract}
Objective: To formulate age- and context-specific complementary feeding recommendations (CFR) for infants and young children (IYC) and to compare the potential of filling population-level nutrient gaps using common sets of CFR across age groups.

Design: Linear programming was used to develop CFR using locally available and acceptable foods based on livelihood- and age-group-specific dietary patterns observed through $24 \mathrm{~h}$ dietary recalls. Within each livelihood group, the nutrient potential of age-group-specific $v$. consolidated CFR across the three age groups was tested.

Setting: Three food-insecure counties in northern Kenya; namely, settled communities from Isiolo ( $n$ 300), pastoralist communities from Marsabit $(n$ 283) and agro-pastoralist communities from Turkana ( $n$ 299).

Subjects: Breast-fed IYC aged 6-23 months ( $n$ 882).

Results: Age-specific CFR could achieve adequacy for seven to nine of eleven modelled micronutrients, except among 12-23-month-old children in agro-pastoralist communities. Contribution of $\mathrm{Fe}, \mathrm{Zn}$ and niacin remained low for most groups, and thiamin, vitamin $\mathrm{B}_{6}$ and folate for some groups. Age-group-consolidated CFR could not reach the same level of nutrient adequacy as age-specific sets among the settled and pastoralist communities.

Conclusions: Context- and age-specific CFR could ensure adequate levels of more modelled nutrients among settled and pastoralist IYC than among agro-pastoralist communities where use of nutrient-dense foods was limited. Adequacy of all eleven modelled micronutrients was not achievable and additional approaches to ensure adequate diets are required. Consolidated messages should be easier to implement as part of a behaviour change strategy; however, they would likely not achieve the same improvements in population-level dietary adequacy as age-specific CFR.
\end{abstract}

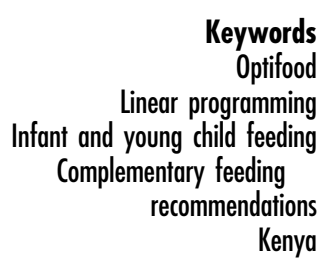

In Kenya, the arid and semi-arid land region experiences high rates of poverty, poor access to basic services and malnutrition $^{(1-3)}$. This region is also one of the most vulnerable in the world to environmental shocks like drought and climate change ${ }^{(2)}$. Pastoralism is one of the few livelihoods appropriate for this environment because people can move livestock according to the ever-changing availability of water and pasture ${ }^{(4)}$. However, conflicts associated with resource scarcity are increasingly common and many are no longer able to make a living from pastoralism. As a result, pastoralists may transition to a sedentary existence, settled either in small rural villages or larger towns. However, moving from a pastoralist to an agro-pastoralist or settled livelihood status often further impoverishes families and many survive on a combination of food aid, small income earned through production of firewood or charcoal, gathering wild foods, fishing or $\operatorname{begging}^{(4,5)}$.

The US Agency for International Development (USAID)funded 'Resilience and Economic Growth in Arid Lands Improving Resilience' (REGAL-IR) project works in Garissa, Isiolo, Marsabit, Turkana and Wajir counties to 
build the capacity of communities to cope with and rebound from shocks such as recurring drought. REGAL-IR interventions support local structures to improve the social, economic and environmental conditions that contribute to nutritionally inadequate infant and young child (IYC) diets and high rates of child stunting ${ }^{(6,7)}$. At the same time, the project aims to improve nutrition outcomes through complementary feeding behaviour change interventions. The Global Alliance for Improved Nutrition (GAIN) was requested by USAID and the REGAL-IR project implementer, African Development Solutions (Adeso), to identify dietary strategies that would contribute to improving the nutrient adequacy of IYC diets. Based on this directive, we identified two main objectives that needed to be addressed: (i) identifying nutrient requirements that are currently not being met in IYC diets, together with the potential of local foods to improve the nutrient quality of their diets; and (ii) identifying cultural-ecological determinants of IYC feeding that serve as facilitators or barriers for the implementation of dietary improvement strategies. Examination of these two challenges required different study designs and methods. Therefore, we created two streams of inquiry: (i) nutrient gap analysis and development of complementary feeding recommendations (CFR); and (ii) examination of socio-ecological determinants using the GAIN-initiated Focused Ethnographic Study (FES) of the determinants of IYC feeding. The present paper reports the results of the first stream of inquiry aimed at developing CFR; the results of the FES study are reported elsewhere ${ }^{(8)}$.

The ' $1000 \mathrm{~d}$ ' from conception to age 2 years is widely recognized as a window of opportunity for the prevention of malnutrition and its short- and long-term consequences ${ }^{(9,10)}$. The longest stage in this window is the period of complementary feeding, which ideally starts at 6 months of age and continues up to 2 years of age, in which IYC move from being exclusively breast-fed to receiving nutrients from a range of foods in addition to breast milk. Achieving nutrient adequacy during this period is challenging as IYC eat in small amounts and nutrient adequacy can only be achieved through the consumption of nutrient-dense foods ${ }^{(11,12)}$. Developing CFR to improve nutrient adequacy is further complicated by rapid changes in consistency, amount and variety of complementary foods of the IYC diet as an infant ages.

While general IYC feeding guidelines have been developed for international use ${ }^{(13)}$, it is necessary to adapt these to be locally relevant. To facilitate the development of context-specific and realistic CFR for adoption by caregivers, a new software, Optifood, which uses linear programming analysis, was recently developed ${ }^{(14)}$. Optifood provides information on the best combinations of local foods to optimize nutrient intakes and can objectively indicate the extent to which these can supply nutritionally adequate diets for an entire population. The strength of Optifood is the capacity to identify CFR that are specific to the local context in terms of actual dietary practices, likely gaps between intakes and requirements for specific nutrients, and local food availability, which are typically defined by agroecologies and demographic and cultural influences. However, as the analyses used to identify CFR are based on $24 \mathrm{~h}$ dietary recall data representing food intakes specific to certain age groups (i.e. 6-8, 9-11 and 12-23 months), and as the dietary patterns across these age groups can vary, the Optifood-derived CFR can also differ substantially between age groups within a population area. Therefore, once CFR have been objectively selected for each age group within a population area, consideration should be given to adapting the CFR to foods and messages that are consistent, or consolidated, and progressive across age groups.

The analysis presented herein includes nine target groups defined on the basis of three age ranges (6-8 months; 9-11 months; 12-23 months) and three different livelihood groups (settled; pastoralist; agro-pastoralist) found in the REGAL-IR project implementation area. The paper first presents how Optifood was used for each of the nine target groups to identify nutrients for which adequacy cannot be reached or would be difficult to reach using local foods as they are usually consumed, and develops sets of CFR to best ensure nutrient intake adequacy for the population. Following this, based on the results from individual age- and livelihood-specific groups, the paper describes the process of consolidating CFR across age groups within each livelihood group and compares the nutrient adequacy of age-specific $v$. consolidated CFR.

\section{Methods}

\section{Study design}

Cross-sectional dietary and anthropometric data were collected in November and December 2013 from 6-23-month-old breast-fed IYC living in selected arid and semi-arid, rural communities in northern Kenya. The season of the survey is considered a season of 'plenty' because it corresponds to the period when the short rains are expected, pasture for livestock is usually available and when homeproduced food is more available than at other times of the year. The dietary survey was part of a landscape analysis intended to inform the selection of interventions -specifically, behaviour change communication interventions - that could improve nutrient adequacy of IYC diets as part of the REGALIR project. In the present study, these data were analysed using linear programming analyses, in the Optifood software, to develop context-specific CFR.

\section{Participants and sampling}

Three main livelihood groups from three food-insecure counties in northern Kenya were selected to represent distinct agro-ecological zones; namely, settled communities from Isiolo, pastoralist communities from Marsabit and 
agro-pastoralist communities from Turkana. All counties represent sparsely populated $\left(<15\right.$ people $\left./ \mathrm{km}^{2}\right)$, arid areas of the eastern (Isiolo and Marsabit) and Rift Valley (Turkana) regions ${ }^{(3)}$. These areas are characterized by high under- 5 stunting rates $30.9 \%$ in the Rift Valley and $32.8 \%$ in the Eastern region) $)^{(1)}$ and large numbers of impoverished households $^{(2,3)}$.

Communities to be surveyed were selected on the basis of two criteria: (i) the REGAL-IR project was being implemented; and (ii) the majority of the population in the community represented the selected livelihood group for that county. The survey aimed to collect information from ninety-five breast-fed children from each of the three target age groups, i.e. 6-8-, 9-11- and 12-23-month-old children, in each of the three livelihood groups, based on the number of respondents needed to estimate population mean food serving sizes for commonly consumed foods to within $\pm 10 \%(95 \% \mathrm{CI})$ assuming an SD of $50 \%$ of the mean serving sizes. Non-breast-fed IYC were not included in this analysis because the sample size of children that were not receiving breast milk was too small to analyse as a separate Optifood target group. A census was conducted in the selected sub-locations to identify all households with children aged 6-23 months and their breast-feeding status. For children aged 6-11 months, all breast-feeding children were invited to participate; whereas for children aged 12-23 months, a sample of breast-feeding children was randomly selected from each of the sub-location census lists.

\section{Data collection}

Quantitative dietary data were collected for IYC using a multiple-pass $24 \mathrm{~h}$ dietary recall adapted from Gibson and Ferguson $^{(15)}$. In the first pass, the primary caregiver was asked to sequentially recall all foods and drinks consumed by their child during the previous day, after which details such as brand names for commercially processed foods and portion sizes were recalled and recorded. Standard recipe data were collected from each livelihood group for recipes commonly used in IYC feeding ${ }^{(15)}$; for recipes reported to be consumed that were different from standard recipes, information on the ingredients, their amounts and the total cooked weight of the dish was collected during the $24 \mathrm{~h}$ recall interview. Portion sizes were estimated by asking caregivers to show the amount served, and the amount left over after feeding, using real foods; these amounts were weighed on dietary scales, recorded, and the amount consumed by the child was calculated by difference. In addition, a separate $24 \mathrm{~h}$ dietary recall was collected for the primary caregiver following similar methodology.

IYC anthropometric measurements were made in triplicate, by trained enumerators. Weight was measured to the nearest $100 \mathrm{~g}$ with an electronic scale (Seca model 770; Seca, Hamburg, Germany) and length was measured to the nearest $0.1 \mathrm{~cm}$ with a wooden measuring board. General household data relating to sociodemographic characteristics and food/hunger were collected using an intervieweradministered structured questionnaire.

Data were collected by thoroughly trained and supervised field staff. Dietary and anthropometric data were doubleentered and underwent rigorous cleaning prior to analysis.

\section{Data analysis}

Maternal diet quality was assessed using the Women's Dietary Diversity Score, an indicator derived from a single $24 \mathrm{~h}$ dietary recall and calculated as the sum of food groups consumed (from a maximum of ten food groups) ${ }^{(16)}$, and the Household Hunger Scale was used to assess the food security situation ${ }^{(17)}$.

All IYC data were prepared and analysed by strata defined by age group (6-8 months, 9-11 months and 12-23 months) and livelihood group (settled, pastoralist and agro-pastoralist communities). Z-scores for IYC length-for-age and weightfor-length were estimated using WHO Anthro software version 3.1 based on the 2006 WHO Child Growth Standards ${ }^{(18)}$; and children with $Z$-scores $<-2$ were classified as stunted or wasted, respectively.

\section{Linear programming analysis using Optifood}

Optifood version 4.0.9.0 was used to generate a series of optimized modelled $7 \mathrm{~d}$ diets that identified: (i) problem nutrients (i.e. nutrients likely to remain low in IYC diets based on local food sources, as consumed); (ii) the best available food sources to fill nutrient gaps; and (iii) alternative CFR for $7 \mathrm{~d}$ diets that would improve dietary adequacy for eleven nutrients $(\mathrm{Ca}, \mathrm{Fe}, \mathrm{Zn}$, riboflavin, niacin, thiamin, folate and vitamins $\mathrm{A}, \mathrm{B}_{6}, \mathrm{~B}_{12}$ and $\mathrm{C}$ ). These alternative $\mathrm{CFR}$ were then tested, in Optifood, to select the best sets of CFR, using criteria based on predicted population-level nutrient adequacy and minimum diet cost. The process of analysing dietary data and developing CFR with Optifood has been described in detail elsewhere ${ }^{(14,19-21)}$. In the present study, all analyses were done in Modules I to III of Optifood for each of the nine target groups. Specific parameters used in these analyses are described below.

\section{Setting model parameters in Optifood}

The model parameters for Optifood were generated using the dietary survey data, which were entered and processed using CS Dietary software version 1.1 and a Microsoft ${ }^{\circledR}$ Access 2010 program developed to support Optifood (D Wiesmann and E Ferguson, unpublished results). The constraints used in all analyses to ensure realistic modelled diets were: (i) the energy (kilocalorie) content of each modelled diet, which was equal to the average energy requirement for the target group; (ii) the minimum and maximum (generally corresponding to the 10th and 90th percentiles, respectively) number of servings from food groups and food subgroups per week; and (iii) the minimum and maximum grams of each individual food item per week. 
These $7 \mathrm{~d}$ parameters were estimated using individual $24 \mathrm{~h}$ dietary recalls multiplied by 7 to simulate weekly food intakes. The serving sizes, for all food items (grams per meal), were determined as the median portion size for consumers in each target group. All food items reported in the 24 h dietary recalls, for each target group, were included in the analyses with the exception of condiments (spices, salt), foods of no nutritional value (tea), therapeutic foods (i.e. Plumpy'Nut ${ }^{\circledR}$ ) and foods deemed uncommon by local informants.

As the quantity of breast milk consumed was not assessed in the dietary survey, daily intakes were estimated based on an assumption that, on average, breast milk contributes 67 , 55 and $39 \%$ of the median energy requirements for children aged 6-8, 9-11 and 12-23 months, respectively ${ }^{(22)}$. Assuming breast milk energy content of $2.76 \mathrm{~kJ} / \mathrm{g}(0.66 \mathrm{kcal} / \mathrm{g})^{(22)}$, the daily intake of breast milk was estimated as 570, 520 and $420 \mathrm{~g}$ for children aged 6-8, 9-11 and 12-23 months, respectively. The nutrient composition of breast milk for 'developing countries' was assumed ${ }^{(22)}$.

The primary source of food composition data for all individual foods was the US Department of Agriculture's National Nutrient Database, Release $23^{(23,24)}$. Energy and protein requirements for each target group were estimated using the relevant WHO/FAO algorithms and the average body weight by age group taken from the survey data (shown in Table 1) ${ }^{(25,26)}$. The 2004 FAO/WHO Recommended Nutrient Intakes (RNI) were used for all target groups $^{(27)}$. Given that animal-source food consumption was meagre, assumptions for the dietary bioavailability of $\mathrm{Zn}$ and Fe were set at 15 and 5\%, respectively. In addition to energy, protein and fat, a total of eleven micronutrients (listed above) were examined in the Optifood analysis.

\section{Identifying problem nutrients}

Two classifications of problem nutrients, 'absolute' and 'partial', were identified through Optifood analysis. Absolute problem nutrients were defined as those nutrients that were $<100 \%$ of the RNI in the Module II nutritionally best diet and $<100 \%$ of the RNI in the Module III maximized diets modelled without CFR constraints. Partial problem nutrients were defined as those nutrients that were $<100 \%$ of the RNI in the Module II nutritionally best diet, but $\geq 100 \%$ of the RNI in the Module III maximized diets modelled without CFR constraints. This meant that the RNI for that nutrient, in at least one modelled diet, could be achieved using local foods as consumed, but at the expense of meeting the RNI for other nutrients.

\section{Selection of complementary feeding recommendations} Individual CFR selected for screening in Module III were identified in two ways: (i) food groups that had a higher number of servings of foods in the Module II nutritionally best diet than the median observed for those food groups (i.e. food group patterns that have nutritional benefits); and (ii) individual food items that provided $\geq 5 \%$ of the nutrient content for at least five micronutrients in the Module II nutritionally best diet (i.e. the best food sources of nutrients), generally expressed at their food subgroup level.

\section{Testing complementary feeding recommendations}

The individual CFR were first screened in Module III (minimized $7 \mathrm{~d}$ diets) to select a subset of individual CFR for a systematic analysis. To select this subset, the Module III minimized nutrient values of the individual CFR were compared to identify CFR that, when combined, would likely provide the highest levels of all eleven micronutrients modelled. In the systematic analysis, all possible combinations of these selected CFR were tested. In these series of analyses, population-level dietary adequacy for a nutrient was defined as a minimized $7 \mathrm{~d}$ diet value $\geq 65 \%$ of its RNI. Thus, a cut-off of $65 \%$ of the RNI, for the simulated diet with the lowest nutrient content, for each nutrient, was predicted to ensure nutrient adequacy for nearly the entire population.

Consolidation of complementary feeding recommendations Following the selection of the best set of CFR for each livelihood- and age-specific target group, the CFR were compared and consolidated across age groups within each livelihood group with the aim to develop common sets of CFR for each livelihood group. Given the heterogeneity of the study populations, no attempt was made to consolidate CFR across different livelihood groups. The approach used to consolidate CFR across age groups within each livelihood group was to select CFR that were recommended for at least two of the three age groups (i.e. food groups or subgroups with the greatest nutrient contribution). In practice, a CFR proposed for a single age group was eliminated, whereas a CFR proposed for at least two age groups was added to the remaining age groups even if it had not previously been identified as a potential CFR in that target group. Once a consolidated set of CFR was selected, an analysis was carried out to test the percentage of the RNI of modelled nutrients achievable for each target group if consolidated CFR rather than age-specific CFR were used. Age-specific median portion sizes and frequencies of intake were maintained.

\section{Results}

\section{Survey results}

Pastoralist households sampled in Marsabit were predominantly from the Gabra ethnic group (Table 1), while the settled households from Isiolo and the agro-pastoralist households from Turkana were ethnically similar (both from the Turkana ethnic group). Among the settled and pastoralist communities foods were purchased or produced at home in similar proportions, whereas agro-pastoralist communities relied mostly on home production (87\%). The most common livestock owned by households across the three livelihood groups were goats, sheep and cattle. Camel ownership was common among pastoralist Marsabit communities (84\% of households), but uncommon among settled Isiolo and 
agro-pastoralist Turkana communities. Many households in settled and agro-pastoralist communities (48 and 64\% of households, respectively) owned chickens, compared with only a few (8\%) households in pastoralist Marsabit communities.

Among these northern Kenyan populations, a large proportion of households reportedly experienced hunger in the last month and dietary diversity for women was low (Table 1). These data suggest that Turkana agro-pastoralists suffered the greatest limitations in terms of the severity and prevalence of household hunger and limited dietary diversity. Between one-fifth and one-third of the population reported participating in a food programme within the last year (Table 1).

Although a significant percentage of children surveyed experienced growth faltering (Table 1), the prevalence of stunting in all three livelihood groups was less than it was in the national estimates (26.5 and $35.5 \%$ for children aged 12-17 and 18-23 months, respectively) ${ }^{(1)}$. This difference may be related to very different growth patterns among pastoralist populations, whereby pastoral children have been found to grow up thinner but taller than

Table 1 Selected sociodemographic characteristic of breast-fed infants and young children, households and caregivers across three livelihood groups in northern Kenya, November-December 2013

\begin{tabular}{|c|c|c|c|c|c|c|}
\hline Household and caregiver characteristics & \multicolumn{2}{|c|}{$\begin{array}{l}\text { Settled communities } \\
\qquad(n 300)\end{array}$} & \multicolumn{2}{|c|}{$\begin{array}{l}\text { Pastoralist communities } \\
\text { ( } n \text { 283) }\end{array}$} & \multicolumn{2}{|c|}{$\begin{array}{c}\text { Agro-pastoralist } \\
\text { communities }(n \text { 299) }\end{array}$} \\
\hline \multicolumn{7}{|l|}{ Tribe/ethnicity (\% yes) } \\
\hline Turkana & \multicolumn{2}{|r|}{85} & \multicolumn{2}{|r|}{0} & \multicolumn{2}{|r|}{100} \\
\hline Gabra & \multicolumn{2}{|r|}{0} & \multicolumn{2}{|r|}{97} & \multicolumn{2}{|r|}{0} \\
\hline \multicolumn{7}{|l|}{ Main source of food during plentiful season (\%) } \\
\hline Household food production & \multirow{2}{*}{\multicolumn{2}{|c|}{$\begin{array}{l}52 \\
47\end{array}$}} & \multicolumn{2}{|r|}{40} & \multicolumn{2}{|r|}{87} \\
\hline Purchased & & & \multicolumn{2}{|r|}{57} & \multicolumn{2}{|r|}{10} \\
\hline \multicolumn{5}{|l|}{ Household Hunger Score ${ }^{*}$ categories (\%) } & & \\
\hline Little or no hunger in the household $(0-1)$ & \multicolumn{2}{|r|}{24} & \multicolumn{2}{|r|}{56} & \multicolumn{2}{|r|}{6} \\
\hline Moderate hunger in the household $(2-3)$ & \multicolumn{2}{|r|}{71} & \multicolumn{2}{|r|}{38} & \multicolumn{2}{|r|}{88} \\
\hline Severe hunger in the household (4-6) & & 5 & & 7 & & 6 \\
\hline Household participated in a food programme & & 21 & & 33 & & 27 \\
\hline & Mean & SD & Mean & SD & Mean & SD \\
\hline Women's Dietary Diversity Score† (no. of food groups) & 3.4 & 1.5 & 3.3 & 0.9 & 2.7 & 1.2 \\
\hline Schooling of caregiver (\%) & & & & & & \\
\hline Never attended & & 63 & & 81 & & 78 \\
\hline Primary, incomplete & & 19 & & 15 & & 17 \\
\hline Primary, completed & & 11 & & 2 & & 2 \\
\hline Child characteristics & & & & & & \\
\hline No. of children surveyed & & & & & & \\
\hline $6-8$ months & & 91 & & 68 & & 69 \\
\hline 9-11 months & & 104 & & 76 & & 134 \\
\hline $12-23$ months & & 105 & & 139 & & 96 \\
\hline Stunting prevalence $\neq(\%)$ & & & & & & \\
\hline $6-8$ months & & 9.8 & & 10.3 & & 7.5 \\
\hline $9-11$ months & & 11.7 & & 6.5 & & 9.6 \\
\hline $12-23$ months & & 24.8 & & 17.3 & & 18.8 \\
\hline Wasting prevalence§ (\%) & & & & & & \\
\hline $6-8$ months & & 1.1 & & 10.3 & & 19.4 \\
\hline 9-11 months & & 11.7 & & 16.9 & & 25.2 \\
\hline $12-23$ months & & 10.5 & & 19.4 & & 21.9 \\
\hline & Median & $\begin{array}{l}\text { 25-75th } \\
\text { percentile }\end{array}$ & Median & $\begin{array}{l}\text { 25-75th } \\
\text { percentile }\end{array}$ & Median & $\begin{array}{l}\text { 25-75th } \\
\text { percentile }\end{array}$ \\
\hline Body weight $(\mathrm{kg})$ & & & & & & \\
\hline $6-8$ months & 7.5 & $7.1-8.1$ & 7.6 & $6.7-8.2$ & 7.3 & $6.8-8.3$ \\
\hline 9-11 months & 8.2 & $7.4-8.7$ & 8.1 & 7.7-8.7 & 7.8 & 7.3-8.6 \\
\hline $12-23$ months & 9.0 & $8.3-9.7$ & 8.8 & $8.1-9.7$ & 8.9 & $8.1-9.9$ \\
\hline Energy intake from complementary foods\| $(\mathrm{kJ})$ & & & & & & \\
\hline $6-8$ months & 1833 & $1314-2803$ & 1623 & $1213-2314$ & 1084 & $778-1439$ \\
\hline 9-11 months & 2238 & $1531-3222$ & 2050 & $1448-2561$ & 1469 & $862-2008$ \\
\hline $12-23$ months & 2791 & 1962-3724 & 2531 & $1816-3213$ & 1795 & $1029-2745$ \\
\hline
\end{tabular}

*The Household Hunger Score is used to assess the food security situation ${ }^{(17)}$.

†The Women's Dietary Diversity Score is based on ten food groups; women consuming foods from five or more food groups have a greater likelihood of meeting their micronutrient needs than women consuming foods from fewer food groups ${ }^{(42)}$.

¥Stunting is defined by a length-for-age $<-2$ SD from the median of the 2006 WHO Child Growth Standards ${ }^{(18)}$

§Wasting is defined by a weight-for-length $<-2$ SD from the median of the 2006 WHO Child Growth Standards ${ }^{(18)}$.

IIBased on a single $24 \mathrm{~h}$ dietary recall. 
children of agriculturalists ${ }^{(28)}$. It is also notable that a higher percentage of children aged 12-23 months were stunted (length-for-age $Z$-score <-2) among settled households in Isiolo than among the pastoralist communities. This finding is similar to other studies in the region that have found that when pastoralist populations settle the prevalence of stunting increases and the prevalence of wasting decreases ${ }^{(5)}$. The prevalence of wasting was high based on the WHO classification of severity of wasting: 11, 19 and $22 \%$ of children aged 12-23 months were wasted (weight-for-length $Z$-score $<-2$ ) in Isiolo, Marsabit and Turkana, respectively.

Energy contribution from complementary foods increased with age, being highest in the settled communities and lowest in the agro-pastoralist communities. Estimated intakes ranged between $1084 \mathrm{~kJ}$ ( $259 \mathrm{kcal}$ ) for 6-8-month-old infants from the agro-pastoralist communities and $2791 \mathrm{~kJ}$ (667 kcal) for 12-23-month-old children from the settled communities. Across the three livelihood groups surveyed, the reported diets were based almost exclusively on four food groups, namely dairy, grain products, added fats and added sugar. These contributed a high proportion of daily energy intakes from the complementary feeding diets ( $82 \%$ in settled, $89 \%$ in pastoralist and $84 \%$ in agro-pastoralist communities). Dairy (animal milk) was of greatest nutritional importance among pastoralist communities (46\% of energy intake from the complementary diet), of some importance among settled populations ( $28 \%$ of energy intake) and of least relative importance among severely food-insecure, agro-pastoralist communities ( $8 \%$ of energy intake). The dairy and grain foods consumed across livelihood groups were distinct. Camels' milk was predominant among the pastoralists, goats' and cows' milk were most common among the settled populations, and goats' milk and milk powder were consumed among agro-pastoralists. Rice and commercially packaged maize flour were the primary grain foods among settled and pastoralist communities, whereas among agropastoralists, local, low extraction maize flour was consumed. Additionally, potatoes and beans together contributed to energy intake (12\% in settled, $8 \%$ in pastoralist and $11 \%$ in agro-pastoralist communities). Vegetable consumption consisted almost entirely of small amounts of tomato and onion added to recipes, with the exception of the common consumption of amaranth leaves among settled communities. Fruit and non-dairy animal-source foods (i.e. meat, fish, poultry and eggs) were almost completely absent from reported diets.

\section{Linear programming analyses results}

In the final food lists modelled, target groups from settled communities had a higher number and variety of foods available for modelling ( $n$ 57) than pastoralist $(n 35)$ and agro-pastoralist ( $n$ 34) communities, indicative of a lack of variety and availability of food in these latter two livelihood groups.

\section{Problem nutrients}

A number of problem nutrients were identified for each target group (Table 2). Target groups in agro-pastoralist communities had the highest number of problem nutrients (five to seven of eleven modelled micronutrients), followed by pastoralist (three to five) and settled communities (two to four). Zn and Fe were consistently well below their RNI across all modelled diets (as low as $15 \%$ of the requirement for $\mathrm{Fe}$ and $25 \%$ for $\mathrm{Zn}$ in the Module II nutritionally best diet) and were classified as absolute problem nutrients, meaning that their RNI could not be achieved using the foods as modelled. Niacin was a problem nutrient in all but one target group; however, niacin might not be a problem nutrient when the contribution of tryptophan to niacin intakes is taken into account.

\section{Selection of complementary feeding recommendations}

Across all target groups, the best food sources of multiple nutrients, relative to other foods reported, were foods from the subgroups breast milk, animal milk (such as cows' and goats' milk), starchy plant foods (such as potatoes and green bananas) and beans, as shown in Table 3. Best sources of $\mathrm{Fe}$ and $\mathrm{Zn}$, which were identified as absolute problem nutrients across the nine target groups, were fortified maize, black beans, potato, red meat and milk in settled and pastoralist communities, and black beans, whole grains and milk in agro-pastoralist communities (data not shown).

\section{Testing complementary feeding recommendations}

The selected sets of CFR for individual livelihood and age groups are presented in Table 4 . The daily consumption of animal milk and starchy foods (potatoes and green bananas) was recommended in all communities. Other commonly recommended food groups included beans across the three livelihood groups, grain products and vitamin A-fortified fats/oils in settled and pastoralist communities, and vegetables in pastoralist and agro-pastoralist communities. Fruit was included as a CFR only in settled communities, and red meat only among pastoralist communities. As expected, modelled portion sizes and frequencies were generally higher for the older than younger age groups.

As shown in Table 5, the highest number of micronutrients for which adequacy could be ensured at the population level (i.e. the nutrient's Module III minimized nutrient content $\geq 65 \%$ of the RNI), using a combination of three to five CFR, was eight or nine (out of a possible eleven) in settled communities, seven to nine in pastoralist communities and five to eight in agro-pastoralist communities. Even with the best combination of CFR, the Module III minimized nutrient levels remained well below their RNI across all communities for Fe (6-34\% of the RNI) and $\mathrm{Zn}$ (13-47\% of the RNI). Furthermore, the Module III minimized values for vitamin $\mathrm{B}_{6}(42-51 \%$ of the RNI) and folate (54-60\% of the RNI) remained relatively low among 
the older age groups from pastoralist and agro-pastoralist communities, and thiamin requirements were not met ( $47 \%$ of the RNI) among agro-pastoralist communities.

Consolidation of complementary feeding recommendations Consolidated sets of CFR were compared across age groups within each livelihood group (Table 6). In settled communities, the CFR to consume daily portions of animal milks, starchy foods, grain products and beans were common across at least two of the three age groups. The complete set of four CFR could not be modelled in the 6-8-month-old settled group because it surpassed the energy allowance for complementary feeding (we modelled $67 \%$ of energy from breast milk). The consolidated set of these four CFR across 9-23-month-old IYC was able to ensure population-level nutrient adequacy for eight of the eleven modelled nutrients compared with the nine achieved using age-specific sets of CFR. Among pastoralist communities, the age-specific CFR were more diverse and five CFR were common across at least two of the three age groups. The consolidated sets of CFR tested across the three age groups could reach the same level of nutrient adequacy as the original, age-specific sets developed for the younger age groups, but not for 12-23-month-old children. Among agro-pastoralist communities, the original age-specific sets of CFR were almost identical across age groups, with animal milks, starchy foods and beans included for all. Therefore, the consolidated set of CFR did not present any change to the number of nutrients for which $\geq 65 \%$ of the RNI was met in the Module III minimized diets.

\section{Discussion}

The current analysis demonstrates that, among 6-23-month-old IYC from northern Kenya, modifications to current feeding patterns to increase the weekly consumption of specific, nutrient-dense foods can ensure population-level dietary adequacy for five to nine of the eleven examined micronutrients, depending on the target group. Nevertheless, working within the model constraints of the current dietary patterns with regard to the types, frequency and portion sizes of foods consumed, there would still be gaps in the intake adequacy for several nutrients even if these CFR are adopted. The number of nutrients for which gaps still remained was lowest among the settled group (i.e. two or three nutrients $<65 \%$ of the RNI) and highest among agro-pastoralists (i.e. three to six nutrients $<65 \%$ of the RNI). These results are not surprising given the widespread poverty, social instability, hunger and malnutrition in these harsh arid and semi-arid regions of Kenya ${ }^{(8)}$.

The inability of the best combination of local foods to ensure population-level dietary adequacy for all eleven micronutrients reflects the limited number, frequency and 
Table 3 Best sources of nutrients at the food subgroup level for each targeted age group of breast-fed infants and young children across three livelihood groups in northern Kenya, November-December 2013

\begin{tabular}{|c|c|c|c|c|c|c|c|c|c|c|}
\hline \multirow[b]{3}{*}{ Food subgroup } & \multirow[b]{3}{*}{$\begin{array}{l}\text { Example of } \\
\text { food item }\end{array}$} & \multicolumn{9}{|c|}{ No. of nutrients ${ }^{*}$ for which the subgroup was a good source $\dagger$} \\
\hline & & \multicolumn{3}{|c|}{ Settled communities ( $n 300)$} & \multicolumn{3}{|c|}{ Pastoralist communities ( $n$ 283) } & \multicolumn{3}{|c|}{ Agro-pastoralist communities ( $n$ 299) } \\
\hline & & $\begin{array}{l}\text { 6-8-month- } \\
\text { old infants }\end{array}$ & $\begin{array}{l}\text { 9-11-month- } \\
\text { old infants }\end{array}$ & $\begin{array}{l}\text { 12-23-month- } \\
\text { old children }\end{array}$ & $\begin{array}{l}6 \text {-8-month- } \\
\text { old infants }\end{array}$ & $\begin{array}{l}\text { 9-11-month- } \\
\text { old infants }\end{array}$ & $\begin{array}{l}\text { 12-23-month- } \\
\text { old children }\end{array}$ & $\begin{array}{l}6 \text {-8-month- } \\
\text { old infants }\end{array}$ & $\begin{array}{l}\text { 9-11-month- } \\
\text { old infants }\end{array}$ & $\begin{array}{l}\text { 12-23-month- } \\
\text { old children }\end{array}$ \\
\hline Breast milk & Breast milk & 10 & 10 & 10 & 10 & 10 & 10 & 10 & 10 & 10 \\
\hline $\begin{array}{l}\text { Fluid or powdered milk } \\
\text { (non-fortified) }\end{array}$ & Fresh goats' milk & 8 & 8 & 7 & 9 & 8 & 6 & 5 & 6 & 7 \\
\hline Starchy plant foods & Potato & 7 & 6 & 3 & 7 & 7 & 2 & 4 & 3 & 1 \\
\hline $\begin{array}{l}\text { Cooked beans, lentils and } \\
\text { peas }\end{array}$ & Red kidney beans & 0 & 4 & 5 & 4 & 5 & 3 & 4 & 6 & 8 \\
\hline $\begin{array}{l}\text { Whole grains, unenriched/ } \\
\text { unfortified }\end{array}$ & Millet flour & 1 & 5 & 0 & 0 & 0 & 2 & 5 & 3 & 5 \\
\hline Red meat & Goat meat & 1 & 5 & 3 & 3 & 1 & 4 & 4 & 0 & 0 \\
\hline $\begin{array}{l}\text { Enriched/fortified grains, } \\
\text { whole or refined }\end{array}$ & Fortified maize flour & 6 & 1 & 2 & 2 & 2 & 2 & 0 & 0 & 0 \\
\hline $\begin{array}{l}\text { Vitamin A-source dark } \\
\text { green leafy vegetables }\end{array}$ & Kale & 5 & 2 & 3 & 0 & 1 & 0 & 1 & 0 & 0 \\
\hline Vitamin C-rich vegetables & Tomato & 2 & 1 & 1 & 1 & 1 & 2 & 0 & 0 & 0 \\
\hline Broths & Beef broth & 0 & 0 & 1 & 0 & 0 & 0 & 2 & 2 & 1 \\
\hline Margarine (fortified) & $\begin{array}{l}\text { Vitamin A-fortified } \\
\text { margarine }\end{array}$ & 1 & 1 & 1 & 0 & 2 & 0 & 0 & 0 & 0 \\
\hline $\begin{array}{l}\text { Vitamin A-source other } \\
\text { vegetables }\end{array}$ & Butternut squash & 1 & 1 & 1 & 0 & 0 & 0 & 0 & 0 & 0 \\
\hline Other fruit & Mango & 0 & 0 & 0 & 0 & 0 & 0 & 1 & 1 & 1 \\
\hline $\begin{array}{l}\text { Refined grain bread, } \\
\text { unfortified }\end{array}$ & White wheat bread & 0 & 0 & 0 & 0 & 0 & 0 & 0 & 0 & 3 \\
\hline Eggs & Whole chicken egg & 0 & 0 & 0 & 0 & 0 & 0 & 0 & 0 & 2 \\
\hline Vitamin C-rich fruit & Orange & 0 & 0 & 0 & 0 & 0 & 0 & 0 & 0 & 1 \\
\hline Vegetable oil (fortified) & Vitamin A-fortified oil & 0 & 0 & 0 & 0 & 0 & 0 & 0 & 0 & 1 \\
\hline
\end{tabular}

${ }^{*}$ From a maximum of eleven micronutrients assessed in Module II of Optifood.

†A good food source is defined as a food subgroup that contributed $\geq 5 \%$ of a nutrient in the diet that did not take usual observed intake into account. 
Table 4 Complementary feeding recommendations, in addition to the recommendation to breast-feed on demand, for each targeted age group of infants and young children across three livelihood groups in northern Kenya, November-December 2013

\begin{tabular}{|c|c|c|c|c|c|c|}
\hline \multirow[b]{2}{*}{ Food or food group } & \multicolumn{2}{|c|}{ 6-8-month-old infants } & \multicolumn{2}{|c|}{ 9-11-month-old infants } & \multicolumn{2}{|c|}{ 12-23-month-old children } \\
\hline & Servings/week & Serving size $(g / d)$ & Servings/week & Serving size $(g / d)$ & Servings/week & Serving size $(\mathrm{g} / \mathrm{d})$ \\
\hline \multicolumn{7}{|l|}{ Settled communities ( $n$ 300) } \\
\hline Animal milk* & 14 & 40 & 14 & 65 & 21 & 65 \\
\hline Potato or green banana $\dagger$ & 7 & 30 & 14 & 50 & 14 & 50 \\
\hline Grains \& grain products $\ddagger$ & - & - & 7 & 20 & 7 & 20 \\
\hline Beans§ & 7 & 30 & 7 & 30 & 7 & 30 \\
\hline Vitamin A-fortified fats/oils\|l & 7 & 5 & - & - & - & - \\
\hline Fruit & - & - & - & - & 7 & 90 \\
\hline \multicolumn{7}{|l|}{ Pastoralist communities ( $n$ 283) } \\
\hline Animal milk* & - & _- & 14 & 60 & 21 & 70 \\
\hline Potato or green banana $\dagger$ & 7 & 40 & $7-14$ & 40 & - & - \\
\hline Grains \& grain products $\ddagger$ & 7 & 15 & 7 & 25 & 14 & 25 \\
\hline Beans§ & - & - & - & - & 7 & 25 \\
\hline Vitamin A-fortified fats/oils\|l & 7 & 5 & 6 & 10 & - & - \\
\hline Vegetablest† & 7 & 15 & - & - & 14 & 15 \\
\hline 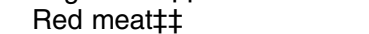 & - & - & - & - & 7 & 25 \\
\hline \multicolumn{7}{|c|}{ Agro-pastoralist communities ( $n$ 299) } \\
\hline Animal milk* & 12 & 40 & 14 & 40 & $14-21$ & 40 \\
\hline Potato or green banana & 7 & 35 & $5-6$ & 50 & $3-4$ & 50 \\
\hline Beans§ & $5-6$ & 20 & 7 & 25 & 7 & 35 \\
\hline Vegetables†† & 7 & 15 & - & - & - & - \\
\hline
\end{tabular}

'-' means that the given food group or subgroup was not among the recommendations.

*'Dairy products': cow, goat, camel and/or sheep milk.

†'Starchy roots \& other starchy plant foods'.

¡'Grains \& grain products' (with at least one fortified option): maize flour, flour mix, millet flour, rice, sorghum and/or spaghetti.

§'Legumes': pinto, red kidney, mung and/or cranberry beans.

II'Vitamin A-fortified fats/oils': vitamin A-fortified margarine.

T'Fruit': banana, orange, papaya and/or passion fruit.

††'Vegetables': kale, spinach, carrot, tomato and/or onion.

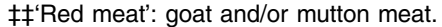

amounts of foods that are good sources of micronutrients in the current diets and from which the modelling process could draw. For example, unlike some other settings where Optifood has been used ${ }^{(19-21,29)}$, the CFR for these northern Kenyan IYC did not include many nutrient-dense animal-source foods such as meat, chicken, eggs or dried fish. These foods were rarely mentioned in the $24 \mathrm{~h}$ recalls and availability of these foods is limited in the local food supply ${ }^{(8)}$. The current analysis indicates that additional modifications to the diet, well outside the current dietary patterns for these IYC, are required to achieve nutritional adequacy of the diet, particularly among agro-pastoralists. Such interventions might include fortified foods, particularly those that are fortified with $\mathrm{Zn}$ and $\mathrm{Fe}$, or home fortification strategies (i.e. micronutrient powders). Similar results have been found, using Optifood analyses, in Indonesia and Cambodia ${ }^{(19,20,29)}$.

The exceptionally poor quality of complementary diets in the agro-pastoralist group was evident from the smaller number of unique foods reported as being consumed and the smaller number of foods present that are considered to be good sources of nutrients, compared with the other two communities. While there were many similarities in the selected CFR between the settled and pastoralist groups, the options for CFR among the agro-pastoralist group were substantially different and much more limited. In the settled and pastoralist groups, the addition of four to five CFR led to a progressively larger number of nutrients that reached $\geq 65 \%$ of the RNI, but with little additional benefit of adding more CFR; while among the agro-pastoralists, the maximum number of nutrients $\geq 65 \%$ of the RNI occurred after selecting only three CFR. This indicates that a broader range of interventions may be needed among agro-pastoralists to achieve nutritional adequacy. This finding is consistent with other studies and the FES conducted in parallel to the present study, which demonstrate that households transitioning from pastoralism to settled livelihood status often experience extreme economic hardship and food insecurity ${ }^{(4,5)}$.

In a similar set of studies conducted among agricultural livelihood groups in western and eastern Kenya, several of the CFR identified were distinct from these northern pastoralist populations, and included fortified porridge mixes, small dried fish, green leafy vegetables and millet ${ }^{(21)}$, and different intervention approaches were recommended $^{(30)}$. These differences, that reflect variances in livelihood groups, agro-ecology, climate and culture, should be acknowledged and used to create context-relevant approaches to improving dietary adequacy in these populations.

The target population of the current analysis encompassed IYC who, in addition to undergoing the marked transition from exclusive breast-feeding to inclusion of special infant foods, to the introduction of - and the then routine consumption - of family foods ${ }^{(31)}$, were from three very distinct livelihood groups in northern Kenya (i.e. nine target groups). 
Optifood's approach of developing context-specific recommendations for individual target populations means that analysis occurs in isolation for each age-based target group (due to differences in food patterns and RNI) and, typically, Optifood projects have focused on only one or two target groups simultaneously ${ }^{(19,20,32,33)}$. The development of common CFR across the age groups in a population, as was done in the present study, would facilitate their promotion and adoption by expecting caregivers to adopt and maintain a single set of practices for the duration of the complementary feeding period as opposed to recommending new foods or practices at the 6-, 8- and 12-month marks. Unlike previous Optifood studies ${ }^{(19-21,32,33)}$, we used a structured methodology in which we selected CFR with a high nutrition impact across the majority of age groups and applied a consolidated set of CFR across all age groups. Age-specific portion sizes and frequency of consumption were maintained to reflect the natural progression towards a larger energy contribution from complementary foods as children get older. The limitations of the CFR consolidation method used here are that children at either the younger or older end of the complementary feeding period may be disadvantaged; and the approach should not necessarily be used in populations where infants $<1$ year old are fed special foods, such as fortified infant porridges. An alternative approach may have been to take CFR that had been identified for only one age group and test them for the remaining two age groups in that livelihood area. The disadvantage in this method would be a greater number of resulting CFR or recommended behaviours, which in practice may be difficult to promote.

A further step towards improving dietary adequacy, which was not done in the current analysis, would be to add and test foods that were not consumed by a specific age group, but were consumed by other age groups within the same area. On the one hand, this approach could lead to CFR that include more nutrient-dense foods available to the population; on the other hand, it could potentially ignore the nuanced evolution of children's diets in the study areas and resulting CFR could prove unsustainable. Further consolidation of CFR may be considered across seasons or in different geographical regions. In the present study, even though consolidated messages would not achieve the same potential improvements to IYC nutrition, the expected benefit is likely still substantial. Although, mathematically speaking, age-specific CFR would achieve the highest nutrient potential, in practice, simpler, streamlined messages for all young children are easier to implement as part of a behaviour change communication strategy $^{(34)}$ and potentially more likely to be adopted.

The analysis using Optifood presented herein provides technical information regarding CFR that could ensure improved dietary adequacy for most individuals in the target groups. A critical next step is to examine the context-specific feasibility, acceptability and affordability of implementing the selected CFR to design a realistic behaviour change communication intervention $^{(14,19,20,35)}$ and develop further 
Table 6 Complementary feeding recommendations (CFR) consolidated across age groups within each livelihood group* and the number of nutrients that achieved $\geq 65 \%$ of the Recommended Nutrient Intake (RNI), in the Module III 'worst-case scenario' analyses, from a maximum of eleven nutrients for the consolidated CFR $\dagger$

\begin{tabular}{|c|c|c|c|}
\hline \multirow[b]{2}{*}{ Food or food group $\ddagger$} & \multicolumn{3}{|c|}{ Recommended minimum servings/week } \\
\hline & $\begin{array}{l}\text { 6-8-month-old } \\
\text { infants }\end{array}$ & $\begin{array}{l}\text { 9-11-month-old } \\
\text { infants }\end{array}$ & $\begin{array}{l}\text { 12-23-month-old } \\
\text { children }\end{array}$ \\
\hline \multicolumn{4}{|l|}{ Settled communities ( $n$ 300) } \\
\hline Animal milk & 14 & 14 & 21 \\
\hline Potato or green banana & 7 & 14 & 14 \\
\hline Grains \& grain products & NF & 7 & 7 \\
\hline Beans & 7 & 7 & 7 \\
\hline $\begin{array}{l}\text { No. of nutrients that achieved } \geq 65 \% \text { of the RNI from a maximum of eleven } \\
\text { nutrients for the consolidated CFR }\end{array}$ & 7 & 8 & 8 \\
\hline \multicolumn{4}{|l|}{ Pastoralist communities (n 283) } \\
\hline Animal milk & $14 \|$ & 14 & 21 \\
\hline Potato or green banana & 7 & 10 & $10 \S$ \\
\hline Grains \& grain products & 7 & 7 & 14 \\
\hline Vitamin A-fortified fats/oils§ & 7 & 6 & $7 \S$ \\
\hline Vegetables & 7 & $7 \S$ & 14 \\
\hline $\begin{array}{l}\text { No. of nutrients that achieved } \geq 65 \% \text { of the RNI from a maximum of eleven } \\
\text { nutrients for the consolidated CFR }\end{array}$ & 8 & 9 & 6 \\
\hline \multicolumn{4}{|l|}{ Agro-pastoralist communities ( $n$ 299) } \\
\hline Animal milk & 12 & 14 & 17 \\
\hline Potato or green banana & 7 & 5 & 3 \\
\hline Beans & 6 & 7 & 7 \\
\hline $\begin{array}{l}\text { No. of nutrients that achieved } \geq 65 \% \text { of the RNI from a maximum of eleven } \\
\text { nutrients for the consolidated CFR }\end{array}$ & 8 & 8 & 5 \\
\hline
\end{tabular}

$\mathrm{NF}$, not feasible within the set constraints.

${ }^{*}$ CFR that were recommended for at least two of the three age groups within a livelihood group (i.e. food groups or subgroups with the greatest nutrient contribution) were included in the age-consolidated set of CFR with the aim to develop consistent messages across each livelihood group.

†The nutrient contribution of the age-consolidated set of CFR was tested for each age group.

¥Foods or food groups as defined in Table 3 .

§The given food group or subgroup was not among the set of recommendations presented in Table 3.

IIThe consolidated CFR could not be tested for this target group because putting them into practice would exceed the equality constraint for energy (kilocalories).

strategies beyond behaviour change communication that are needed to bridge nutrient gaps in the local food supply, particularly important in this context of significant poverty and food insecurity. It is critical to bring the results of the Optifood analysis and FES together to identify opportunities and constraints in applying the CFR, including perceptions of cost, convenience, accessibility and appropriateness of the recommended foods for IYC diets and other social or physical factors that determine accessibility of these foods across seasons ${ }^{(30)}$. This will inform whether the selected foods and their quantities are suitable for promotion in the represented populations, or whether they need to be adapted or substituted to facilitate adoption. There are several factors that may affect adoption of CFR in practice; these include availability of foods on-farm or in the market across different seasons, their cost as well as affordability based on the local economy, food preparation time, individual child preferences for foods, and current beliefs and practices. Food shortage is prevalent among these populations; overall, one-third participated in a food programme within the last year. The cross-sectional dietary survey used as the basis for the Optifood analysis did not collect information on the sources of foods reported in the $24 \mathrm{~h}$ recall. Results of the FES conducted in parallel to the study presented herein showed that many of the forty-eight FES respondents in Turkana received donations of sorghum ( $n$ 25), beans/lentils/split peas ( $n$ 13) and oil $(n 12)^{(8)}$. Food donations were less prevalent in Isiolo and Marsabit, with respectively ten of forty-eight and seven of thirty-six FES respondents reporting having received food. It is recommended that testing of the feasibility and acceptability of these CFR be carried out using tools such as ProPAN ${ }^{(36)}$ or Trials of Improved Practices ${ }^{(37,38)}$ where caregivers are asked to trial and provide feedback on the CFR.

A series of limitations inherent to dietary and Optifood analysis is acknowledged. The analysis is dependent on the quality of the dietary recall data, estimated breast milk intakes, the food composition data and RNI used. As data collection took place during the rainy season, the results cannot necessarily be extrapolated to other seasons. It was not within the scope of the study to collect data across all seasons and develop season-specific CFR. Further, while particular foods appeared in the list of foods consumed by the target population, these foods may not be accessible to all local families or at all times. With respect to the RNI, the $\mathrm{Zn}$ requirement proposed by the WHO/FAO is higher than that proposed by the International Zinc Nutrition Consultative Group ${ }^{(39)}$. Although phytate intake was not directly taken into account, intake was assumed to be relatively high based on the diet type and the bioavailability of $\mathrm{Zn}$ and $\mathrm{Fe}$ was assumed to be low. Similarly, Vitta and Dewey ${ }^{(40)}$ argue 
that the WHO/FAO RNI for Ca may be inflated and therefore propose use of the more recent US Institute of Medicine Dietary Reference Intake for analysis of $\mathrm{Ca}$ intake adequacy $^{(41)}$. The estimation of niacin inadequacy is limited by the lack of information on tryptophan conversion. For breast milk, the estimated energy contributions from the proposed CFR were systematically lower than the observed energy intakes from complementary foods, which suggests that the surveyed children may be consuming less breast milk than modelled. Breast milk was an important food source for ten of the eleven nutrients modelled (Table 3); therefore, differences in the modelled and actual breast milk intakes could modify our findings.

In summary, the present study highlights the potential value and limitations in determining age- and populationspecific CFR that take into account the actual, local dietary patterns and available foods. Localized CFR can provide much more specific and nutritionally relevant recommendations than general IYC feeding guidelines. However, the complexity and specificity of localized CFR which aim to simultaneously meet multiple nutrient requirements need to be balanced with the practicalities of feeding IYC and comprehensibility of behaviour change messages. We found trade-offs in the nutrient adequacy of the CFR as a result of simplifying and consolidating CFR across age groups.

\section{Acknowledgements}

Acknowledgements: The authors thank Abdelrahman Lubowa for training on the use of CS Dietary software and leading the processing of dietary data, Rebecca Kanter for extensive cleaning of dietary data, and Doris Wiesmann for designing and providing the Microsoft Access software program. Financial support: This work was made possible by the generous support of the American people through the support of the REGAL-IR project led by Adeso with funding of the US Government's Feed the Future (FtF) initiative. The contents are the responsibility of GAIN and do not necessarily reflect the views of the US Government or Adeso. Conflict of interest: All authors reported no conflicts of interest. Authorship: A.T., C.H., P.C. and E.L.F. formulated the research questions and designed the study; C.H. and P.C. conducted the research; all authors analysed data; and M.V., F.A.K., A.T. and C.H. wrote the paper. M.V. and F.A.K. had primary responsibility for the final content. All authors read and approved the final manuscript. Etbics of buman subject participation: Ethical approval was obtained from the Ethics Review Committee at Kenyatta University, and a research permit was obtained from the National Council for Science and Technology, Kenya. The research complied with the Helsinki Declaration as revised in 1983. Informed consent was sought from the local administrators at the study sites and from the caregiver of each participating child.

\section{References}

1. Kenya National Bureau of Statistics \& ICF Macro (2014) Kenya Demographic and Health Survey 2014. Calverton: MD: KNBS and ICF Macro.

2. United Nations Development Programme (2013) Kenya National Human Development Report 2013. Kenya: UNDP.

3. Commission of Revenue Allocation (2011) Kenya County Fact Sheets. Nairobi: CRA Kenya.

4. Oxfam International (2008) Survival of the Fittest: Pastoralism and Climate Change in East Africa. Oxfam International; available at https://www.oxfam.org/sites/www.oxfam.org/files/ file_attachments/bp116-pastoralism-climate-change-eafrica0808_14.pdf

5. Fratkin E, Nathan MA \& Roth EA (2006) Is Settling Good for Pastoralists? The Effects of Pastoral Sedentarization on Children's Nutrition, Growth, and Health among Rendille and Ariaal of Marsabit District, Northern Kenya. Nairobi: International Livestock Research Institute.

6. Stewart CP, Iannotti L, Dewey KG et al. (2013) Contextualising complementary feeding in a broader framework for stunting prevention. Matern Child Nutr 9, 27-45.

7. UNICEF (1990) Strategy for Improved Nutrition of Children and Women in Developing Countries. New York: UNICEF.

8. Thuita FM \& Pelto GH (2014) Infant and Young Child Feeding Behaviors, Beliefs, Contexts and Environments in Isiolo, Marsabit and Turkana Counties - Kenya: Report on the Focused Ethnographic Studies in the REGAL-IR ('Resilience and Economic Growth in the Arid Lands - Improving Resilience') Program Area. Geneva and Washington, DC: Global Alliance for Improved Nutrition.

9. Bhutta ZA, Das JK, Rizvi A et al. (2013) Evidence-based interventions for improvement of maternal and child nutrition: what can be done and at what cost? Lancet 382, 452-477.

10. Black RE, Allen LH, Bhutta ZA et al. (2008) Maternal and child undernutrition: global and regional exposures and health consequences. Lancet 371, 243-260.

11. Solomons NW \& Vossenaar M (2013) Nutrient density in complementary feeding of infants and toddlers. Eur J Clin Nutr 67, 501-506.

12. Dewey KG (2013) The challenge of meeting nutrient needs of infants and young children during the period of complementary feeding: an evolutionary perspective. J Nutr 143, 2050-2054.

13. Pan American Health Organization (2003) Guiding Principles for Complementary Feeding of the Breastfed Child. Washington, DC: PAHO.

14. Daelmans B, Ferguson E, Lutter CK et al. (2013) Designing appropriate complementary feeding recommendations: tools for programmatic action. Matern Child Nutr 9, Suppl. 2, 116-130.

15. Gibson RS \& Ferguson EL (2008) An Interactive 24-Hour Recall for Assessing the Adequacy of Iron and Zinc Intakes in Developing Countries. HarvestPlus Technical Monograph no. 8. Washington, DC and Cali: International Food Policy Research Institute and International Center for Tropical Agriculture.

16. Food and Agriculture Organization of the United Nations \& Food and Nutrition Technical Assistance II Project, FHI 360 (2016) Minimum Dietary Diversity for Women: A Guide for Measurement. Rome: FAO.

17. Ballard T, Coates J, Swindale A et al. (2011) Household Hunger Scale: Indicator Definition and Measurement Guide. Washington, DC: Food and Nutrition Technical Assistance II Project, FHI 360.

18. World Health Organization Multicentre Growth Reference Study Group (2006) WHO Child Growth Standards: Length/Height-for-Age, Weight-for-Age, Weight-for-Length, 
Weight-for-Height and Body Mass Index-for-Age: Methods and Development. Geneva: WHO.

19. Santika O, Fahmida U \& Ferguson EL (2009) Development of food-based complementary feeding recommendations for 9- to 11-month-old peri-urban Indonesian infants using linear programming. J Nutr 139, 135-141.

20. Skau JK, Bunthang T, Chamnan C et al. (2014) The use of linear programming to determine whether a formulated complementary food product can ensure adequate nutrients for 6- to 11-month-old Cambodian infants. Am J Clin Nutr 99, $130-138$

21. Ferguson E, Chege P, Kimiywe J et al. (2015) Zinc, iron and calcium are major limiting nutrients in the complementary diets of rural Kenyan children. Matern Child Nutr 11, Suppl. 3, 6-20.

22. Brown KH, Dewey KG \& Allen LH (1998) Complementary Feeding of Young Children in Developing Countries: A Review of Current Scientific Knowledge. Geneva: WHO

23. Hotz C, Ferguson E, Kennedy G et al. (2011) Standard Operating Procedures for the Compilation of the Optifood Food Composition Table. Version 9. Washington, DC: Academy for Educational Development/Food and Nutrition Technical Assistance Project.

24. US Department of Agriculture, Agricultural Research Service (2010) USDA National Nutrient Database for Standard Reference, Release 23. http://www.ars.usda.gov/ba/bhnrc/ ndl (accessed May 2015).

25. United Nations University, World Health Organization \& Food and Agriculture Organization of the United Nations (2004) Human Energy Requirements. Report of a Joint FAO/WHO/ UNU Expert Consultation, Rome, 17-24 October 2001. FAO Food and Nutrition Technical Report Series no. 1. Rome: FAO.

26. World Health Organization, Food and Agriculture Organization of the United Nations \& United Nations University (2007) Protein and Amino Acid Requirements in Human Nutrition. Report of a Joint WHO/FAO/UNU Expert Consultation. WHO Technical Report Series no. 935. Geneva: WHO.

27. World Health Organization \& Food and Agriculture Organization of the United Nations (2004) Vitamin and Mineral Requirements in Human Nutrition, 2nd ed. Geneva: WHO.

28. Chotard S, Mason JB, Oliphant NP et al. (2010) Fluctuations in wasting in vulnerable child populations in the Greater Horn of Africa. Food Nutr Bull 31, 3 Suppl., S219-S233.

29. Fahmida U, Santika O, Kolopaking R et al. (2014) Complementary feeding recommendations based on locally available foods in Indonesia. Food Nutr Bull 35, 4 Suppl., S174-S179.

30. Hotz C, Pelto G, Armar-Klemesu M et al. (2015) Constraints and opportunities for implementing nutrition-specific, agricultural and market-based approaches to improve nutrient intake adequacy among infants and young children in two regions of rural Kenya. Matern Child Nutr 11, Suppl. 3, 39-54.

31. World Health Organization \& UNICEF (2003) Global Strategy for Infant and Young Child Feeding. Geneva: WHO.

32. Darmon N, Ferguson E \& Briend A (2002) Linear and nonlinear programming to optimize the nutrient density of a population's diet: an example based on diets of preschool children in rural Malawi. Am J Clin Nutr 75, 245-253.

33. Ferguson EL, Darmon N, Fahmida U et al. (2006) Design of optimal food-based complementary feeding recommendations and identification of key 'problem nutrients' using goal programming. J Nutr 136, 2399-2404.

34. Roberto CA \& Kawachi I (2014) Use of psychology and behavioral economics to promote healthy eating. Am J Prev Med 47, 832-837.

35. Fahmida U, Kolopaking R, Santika O et al. (2015) Effectiveness in improving knowledge, practices, and intakes of 'key problem nutrients' of a complementary feeding intervention developed by using linear programming: experience in Lombok, Indonesia. Am J Clin Nutr 101, 455-461.

36. Pan American Health Organization \& UNICEF (2013) Process for the Promotion of Child Feeding (ProPAN), 2nd ed. Washington, DC: PAHO.

37. Dickin KL \& Seim G (2013) Adapting the Trials of Improved Practices (TIPs) approach to explore the acceptability and feasibility of nutrition and parenting recommendations: what works for low-income families? Matern Child Nutr 11, 897-914.

38. Dickin KL, Griffiths M \& Piwoz E (1997) Designing by Dialogue: A Program Planners' Guide to Consultative Research for Improving Young Child feeding. Washington, DC: Academy for Educational Development.

39. Brown KH, Rivera JA, Bhutta Z et al. (2004) International Zinc Nutrition Consultative Group (IZiNCG) technical document $\# 1$. Assessment of the risk of zinc deficiency in populations and options for its control. Food Nutr Bull 25, 1 Suppl. 2, S99-S203.

40. Vitta B \& Dewey K (2012) Identifying Micronutrient Gaps in the Diets of Breastfed 6-11-month-old Infants in Bangladesh, Ethiopia and Viet Nam Using Linear Programming. Washington, DC: Alive \& Thrive.

41. Institute of Medicine (2011) Dietary Reference Intakes for Calcium and Vitamin. D. Washington, DC: National Academies Press.

42. European Union, Food and Agriculture Organization of the United Nations, US Agency for International Development et al. (2014) Women's Dietary Diversity Project (WDDP). Introducing the Minimum Dietary Diversity - Women (MDD-W) Global Dietary Diversity Indicator for Women. Washington, DC: Food and Nutrition Technical Assistance III Project, FHI 360. 